\title{
Projeto: Reestruturação produtiva e qualificação
}

\author{
Márcia de Paula Leite* \\ Cibele Saliba Rizek**
}

\begin{abstract}
RESUMO: À guisa de apresentação do Projeto "Reestruturação produtiva e qualificação", este texto é um relatório parcial de um ano das diferentes pesquisas. Ele discute os primeiros achados dos vários subprojetos que compõem o projeto, analisando especialmente as segmentações presentes no mundo do trabalho.
\end{abstract}

Palavras-chave: qualificação, optimização do trabalho, formação profissional, reestrutuação produtiva, negociação trabalhista

Introdução

A questão dos novos requisitos de qualificação em face do atual processo de reestruturação produtiva das empresas é uma questão extremamente polêmica. Embora haja um certo consenso entre os estudiosos de que o novo paradigma produtivo tende a elevar os requisitos de qualificação da mão-de-obra de uma maneira geral quando comparado ao paradigma taylorista, há ainda uma série de pontos obscuros nesse processo, cuja análise se torna fundamental quando se pensa em discutir a questão de forma mais aprofundada.

Tais pontos obscuros relacionam-se fundamentalmente às segmentações do mercado de trabalho e às diferentes formas de inserção de trabalhadores e trabalhadoras no processo produtivo, as quais se relacionam por sua vez a distintos padrões de uso do trabalho e a trajetórias diferenciadas de reestruturação. Convém lembrar que para

* Professora do Decisae/Unicamp e pesquisadora do CNPq.

** Professora da USP/São Carlos. 
serem analisadas em toda sua complexidade, essas diferentes formas de inserção necessitam ser consideradas a partir da concepção da qualificação como uma construção social (Leite e Posthuma 1996, p. 64), na medida em que só ela permite apreender as representações sociais presentes no mercado de trabalho, a partir das quais as gerências tendem a exclusivisar determinados postos de trabalho a alguns grupos de trabalhadores em função de características atributivas como sexo, idade e cor.

Essas questões serão discutidas aqui a partir dos "achados" preliminares dos diferentes subprojetos, os quais serão analisados à luz das questões teóricas levantadas pela bibliografia especializada no tema. Para tanto, o texto será organizado em dois tópicos fundamentais. No primeiro, dedicado ao exame das distintas estratégias de reestruturação das empresas, discutiremos a difusão de tais estratégias em relação aos vários setores produtivos e suas diferentes implicações para a qualificação; no segundo, aprofundaremos a análise do novo paradigma produtivo e as segmentações do mercado de trabalho.

Estratégias de reestruturação e qualificação

A idéia de que as transformações produtivas que vêm ocorrendo nas últimas décadas estariam forjando um novo paradigma produtivo tem se tornado cada vez mais evidente. Não só (como a bibliografia especializada tem fartamente documentado) os princípios que estiveram por trás da produção em massa que caracterizou o paradigma taylorista/ fordista vêm sendo continuamente substituídos pela lógica da flexibilidade, como as regulamentações sobre as quais se baseou a relação entre o capital e o trabalho no paradigma anterior vêm perdendo cada vez mais sua efetividade.

O novo paradigma produtivo na discussão internacional

A constatação de que nos encontramos diante de um novo paradigma produtivo - hoje difícil de ser contestada - não significa, entretanto, que o mundo da produção caminhe inexoravelmente em direção a um modelo único de reestruturação. Pelo contrário, a bibliografia tem insistido no fato de que, embora estejamos diante do do- 
mínio de novos conceitos de produção que se difundem rapidamente pelos quatro cantos do mundo, os caminhos que vêm sendo seguidos pelas empresas na busca da produtividade não são homogêneos. Com efeito, há já um conjunto não desprezível de estudos que têm sublinhado a existência de diferentes trajetórias, os quais têm chamado a atenção para a possibilidade de convivência de estratégias muito diferentes. Nesse contexto, novos conceitos têm sido criados buscando elucidar a diversidade da realidade.

A começar com o alerta de Kern e Schumann (1988) para o fato de que o processo estaria engendrando ao mesmo tempo setores "ganhadores" e "perdedores", passando pela dicotomia entre o high road e o low road proposta por Pyke e Sengenberger (1992), ou ainda pelas alternativas de estratégias negociadas e não negociadas discutidas por Babson, a bibliografia vem dando conta de uma grande diversidade de trajetórias que se encontram não só nas duas extremidades dessas bipolarizações, mas ainda entre as inúmeras possibilidades diferentes que se encontram entre esses extremos.

Talvez o mais importante a discutir a esse respeito seriam os vários recortes que estariam na base dessas diferentes trajetórias, o que permitiria dar um mínimo de organização no enorme espectro de diferentes possibilidades que se nos apresentam.

Assim, por exemplo, os conceitos de high road e low road emergem como centrais nessa discussão não só por partirem do princípio de que o caminho não é unívoco, mas também por permitirem uma reflexão sobre quais as variáveis que estariam na base desses diferentes caminhos. Nessa discussão, certamente as diferenças relacionadas à história de cada país e às diferentes culturas nacionais desempenham um papel importante que permite elucidar, por exemplo, por que as estratégias high road tendem a ser mais comuns nos países desenvolvidos e, entre eles, especialmente os europeus, onde a experiência do estado do bem-estar social assegurou não só a integração social da classe trabalhadora - que permitiu a esses países contar com um estoque significativo de mão-de-obra qualificada antes mesmo da difusão dos novos conceitos de produção - como o desenvolvimento de relações mais pactuadas entre capital e trabalho. ${ }^{2}$

Nesse contexto, levar em conta as preocupações de Babson (1995) sobre as relações industriais se apresenta como mais um elemento importante no sentido de elucidar os recortes. Com efeito, ao lembrar que embora o high road possa ser a estratégia mais eficiente a longo 
prazo, como o objetivo das empresas é também o lucro máximo a curto prazo, as pressões do mercado tendem a tornar as estratégias baseadas na utilização do trabalho barato numa opção freqüente; o autor alerta para o papel dos sindicatos e das relações industriais na definição de um modelo mais virtuoso.

Nesse sentido, a presença de sindicatos fortes não é indiferente para as características que o processo de modernização tecnológica vem adquirindo. Pelo contrário, as experiências dos países em que os sindicatos - em função de uma longa história de organização e de luta - vêm logrando manter seu poder de negociação, como Alemanha, Suécia e Itália, indicam que a pressão sindical desponta como um fator central na definição de um modelo mais voltado para a utilização da mão-de-obra como um bem a ser valorizado e mais assentado na flexibilidade interna que na externa, assim como para o predomínio de formas de organização menos fragmentadoras do mercado de trabalho.

O mesmo raciocínio é válido também quando se pensa na diferenciação por setor: não há dúvida de que a concentração das tendências mais virtuosas de organização e gestão do trabalho nos setores historicamente mais bem organizados, como o metalúrgico e o automobilístico, tem a ver não apenas com características dos processos de produção, mas também com a histórica capacidade de organização dos trabaIhadores desses setores.

A compreensão dessa questão é de enorme importância para a discussão da difusão das estratégias mais virtuosas e evidencia a incorreção em que caem os autores que generalizam as características do trabalho no setor automobilístico para o conjunto do setor industrial. Mais que isso, ela é fundamental quando se pensa na fábrica não só como o campo da racionalidade, onde o que está em jogo são as necessidades da produção, mas também como o reflexo de relações e interações sociais entre agentes com diferentes interesses, culturas e práticas sociais.

Esse fato coloca a realidade do mundo da produção numa situação bastante complexa e contraditória em que, ao mesmo tempo em que poderia se encontrar uma convergência entre os interesses dos sindicatos e trabalhadores e os das empresas no que se refere à busca de um trabaIho mais qualificado, estável, participativo e bem pago, na realidade o que tende a acontecer é o inverso: a não ser nos locais e setores onde o movimento sindical tem demonstrado grande poder de pressão, a maior parte das empresas vem isolando os sindicatos do processo e implementando 
as inovações de forma unilateral, de modo a poder cortar os custos com mão-de-obra, o que acaba por jogá-las nas estratégias low road. Na verdade, quando se analisa o processo no que se refere às relações industriais de uma maneira geral, o que encontramos é uma tendência bastante regressiva em que, escapando a toda e qualquer forma de controle que os movimentos sociais lograram construir ao longo do último século (e que não só garantiam direitos fundamentais aos trabalhadores, como impunham importantes restrições sociais à atuação do capital), as empresas vêm anulando conquistas históricas dos trabalhadores, aprofundando a segmentação do mercado de trabalho e promovendo um processo inédito de concentração da renda mundial, embora também aqui não se possa considerar o processo de maneira unívoca ou homogênea.

Finalmente, valeria lembrar também as reflexões de Kern e Schumann (1988), para quem as diferenças entre as lógicas inerentes aos vários setores produtivos, a partir dos diferentes nichos de mercado a que eles se destinam, são também uma variável importante na elucidação da questão. De fato, para esses autores a preocupação com a qualidade não assume a mesma importância para todos os setores industriais. Pelo contrário, de acordo com a dinâmica do mercado, determinados setores (especialmente os voltados para a produção de produtos de baixo valor agregado, destinados ao consumo popular) têm sua estratégia muito mais centrada na questão do preço do que na da qualidade, conforme elucidam os autores ao comparar a produção de automóveis com a de margarina, ressaltando importantes diferenças:

a) ....a indústria de automóveis tem de seguir uma política com relação ao trabalho que lhe assegure as altas exigências de qualidade... Os estímulos salariais e os controles pessoais têm se manifestado como instrumentos insuficientes para garantir estas exigências empresariais específicas. Pelo contrário, os trabalhos de embalagem e transporte na fabricação de margarina praticamente carecem de qualquer dimensão de qualidade. Em princípio não existem dificuldades para assegurar a prestação desejada mediante estímulos salariais e controles.

b) Durante os últimos anos tem aumentado na indústria de automóveis a proporção de postos de trabalho de montagem mais complexos e necessitados de familiarização; em conseqüência, uma mudança de pessoal representa hoje em dia um importante fator de custo. Pelo contrário, na fabricação de margarina os postos de tra- 
balho corrente voltam a ocupar-se quase sem gasto destacável em familiarização, quer dizer, não existem gastos de qualificação por troca de pessoal. (Kern e Schumann 1988, pp. 345-346)

Na verdade, o que parece ir se evidenciando é que, embora uma nova dinâmica venha se impondo à produção industrial como um todo, a inovação pode ser perseguida de diversas formas, as quais incluem, inclusive, como alerta Zarifian (1993), um processo de "retaylorização". Tal possibilidade estaria colocada, segundo o autor, quando o processo não incorpora uma mudança no conceito de produtividade, que permaneceria "entendido como um conceito operacional centrado na relação quantitativa - produção por horas/homem" (relatório Liedke p. 14).

Essas reflexões podem ser corroboradas ainda pela análise da formação profissional, se levarmos em conta que ela dificilmente pode ser pensada como um antídoto às alternativas não qualificantes. Com efeito, conforme explicita o relatório do Dieese, há vários indícios nos exemplos internacionais de que, se por um lado, é verdade que as empresas vêm incrementando seus esforços voltados para a qualificação, há também, por outro lado, muita mãode-obra qualificada que não está conseguindo ser absorvida pelas empresas. Isso significa que embora a disponibilidade de mão-de-obra qualificada seja condição necessária para que as empresas possam seguir uma estratégia virtuosa, ela não é suficiente para a garantia de tal caminho.

Esses recortes se apresentam, nesse sentido, como fundamentais para se poder pensar as diferentes estratégias de reestruturação das empresas, na medida em que elucidam as relações entre as distintas experiências e a história pregressa dos vários países, as relações que se estabelecem entre os atores sociais e a capacidade de organização sindical, ou mesmo as várias lógicas setoriais. Nesse sentido, é deles que deveremos partir para pensar a realidade que vem sendo estudada pela pesquisa, a qual se centrará na discussão das semelhanças e diferenças das distintas trajetórias.

O novo paradigma produtivo no Brasil:

Os "achados" da pesquisa

O que parece ser possível constatar pela leitura dos relatórios e das experiências apresentadas é uma dimensão de diversidade e de riquezas de situações que se escondem e se revelam sob o 
título Reestruturação produtiva. Como se solidarizam estas diversidades? A partir de que matriz interpretativa é possível (ou desejável) qualificá-las, encontrar-Ihes uma lógica? Esta dimensão norteará o comentário sobre as situações que compõem o universo empírico desta pesquisa.

Uma das dimensões transversais às diversas situações de pesquisa nos aponta uma discussão que, de certa forma, dirige nosso olhar para uma diversidade de lógicas articuladas em um mesmo processo de reestruturação. Ou seja, as muitas situações de reestruturação se articulam a partir de lógicas distintas de acordo com a região, com o setor produtivo, com práticas fabris distintas, com diversas modalidades de verticalização e horizontalização da produção. Tal diversidade, entretanto, já era uma característica das formas tayloristas/fordistas anteriores. Não é demais relembrar a presença de lógicas diversas no interior mesmo de cada região, setor ou subsetor, momentos produtivos etc., lógicas que matizam, conferem sentidos diversos e formas diversas de configuração das novas práticas e direções da reestruturação produtiva. O que ainda parece estar indicado é uma dimensão pela qual as fortes segmentações e direções distintas indicam um diferencial que pode se revestir de maiores disparidades, proveniente de um processo de aprofundamento das formas de segmentação e ressegmentação do mercado de trabalho, das iniciativas e dos processos de transformação técnica, das muitas e variadas formas pelas quais a produção se encadeia misturando setores e unidades produtivas anteriormente muito mais estanquizadas.

Deste ponto de vista, estamos diante de um processo complexo - a reestruturação produtiva - que nos remete a um conjunto de novas formas de divisão do trabalho e de flexibilizações que, ao contrário do que se anuncia em um primeiro momento, supuseram processos decisórios, criaram e obliteraram conflitos, impactaram contextos diversos que, longe de se homogeneizarem, reforçaram, recriaram e desfizeram formas anteriores de segmentação.

Pode-se, assim, apontar tendências à homogeneização de alguns elementos em torno da questão reestruturação produtiva e qualificação, e outros de ressegmentação, redivisão, produzindo uma realidade do trabalho que é muito mais múltipla do que a simples dualização. Assim, um dos elementos fortemente associados à esfera de uma das dimensões da qualificação é o aumento da escolaridade formal requerida, como se pode ver pelos comentários abaixo: 
Os primeiros resultados da pesquisa ora em andamento indicam estar ocorrendo uma elevação das exigências de escolaridade para os empregados ligados à produção nas indústrias de transformação... Ainda que apresentando características bem diferenciadas por setor de atividade (...) entre os ramos considerados em cada setor, entre e intra-empresas investigadas, em decorrência das estratégias competitivas adotadas em cada organização, dos mercados de produtos (...) e dos critérios adotados internamente a cada empresa, de recrutamento da mão-de-obra empregada (por exemplo, composição por sexo, idade, escolaridade), em todos os setores investigados alteram-se os conhecimentos e os perfis de habilidades requeridos com a introdução de sistemas digitais e, principalmente, a partir da incorporação de técnicas de racionalização do processo de trabalho, quer seja em torno do conceito de "produção enxuta" (...) ou como processo de "retaylorização"... (relatório Liedke p. 18)

Também no relatório do subprojeto 6 , a questão do aumento da escolaridade da força de trabalho aparece com clareza, especialmente no tratamento de dados secundários (pp. 47-49), bem como a dimensão que aponta uma razão inversa entre escolaridade e rotatividade. $O$ mesmo aumento dos níveis de escolaridade aparece no relatório do Subprojeto Trabalho e Qualificação no Complexo Químico Paulista (Rizek e Mello e Silva), enfatizando a questão da providência da escola propedêutica nas empresas, assim como na realidade mineira, como aponta o relatório de Crivellari, em relação à indústria de autopeças de Minas Gerais. Aqui, entretanto, cabe uma curiosa observação: ao mesmo tempo em que se homogeneiza uma tendência ao aumento da escolaridade da força de trabalho que se identifica e é identificada como "a peãozada", os "peões", parece haver uma "queda na especialização dos consultores e uma grande concorrência entre eles" (relatório Crivellari). A questão da escolaridade, que se coloca em nível de uma análise macro, certamente recebe fortes mediações em níveis intermediário e micro, assim como pode se revestir ou não de um processo de diminuição das diferenças simbólicas entre "técnicos" e "peões". Estas variações parecem se colocar na chave de uma outra dimensão que incide sobre a análise das faces das novas formas de gestão, negociadas ou não, conflitivas de modo mais ou menos aberto, no interior das empresas.

Os caminhos de reestruturação se revestem, assim, de elementos homogêneos para em seguida tomar uma forma extremamente heterogênea tanto intra-setorialmente como entre e intra-regionalmente. Até mesmo a velha e continuamente renovada questão da divisão sexual do trabalho é fortemente matizada pela dimensão setorial no interior da mesma 
região ou do mesmo setor, como apontam os relatórios relativos ao Complexo Químico Paulista e o que diz respeito ao Rio Grande do Sul, onde se enfatiza, entre outras, a diferença entre a inserção feminina no setor bancário e na indústria de transformação (relatório Liedke p. 21).

Dessa maneira, pode-se observar que, se há elementos homogêneos, como parece ser o caso de um aumento da escolaridade (que obedece a níveis requeridos pela demanda, mas que também pode estar apontando para um outro tipo de comportamento da oferta de trabalho - ver relatório Castro, em especial texto elaborado por A. Comim), por outro lado, a significação destes níveis de escolaridade pode não se vincular a uma transformação real das qualificações requeridas por novos conteúdos do trabaIho, estando eles referidos a formas de racionalização do trabalho e da vida (relatório Rizek e Mello e Silva) e/ou em um patamar de adesão do trabaIhador individual (relatório Castro), ou ainda a novas fronteiras de demarcação de diferenças simbólicas entre níveis hierárquicos.

Como se pode decodificar esta combinação entre homogeneidades e heterogeneidades? O que é comum nos processos variados de reestruturação produtiva observados pelos vários pesquisadores? Mais do que isso, é possível atribuir estes elementos comuns a uma matriz estrutural que permanentemente se inscreve "na natureza das coisas", isto é, em um movimento de objetivação de determinações inelutáveis de ordem técnica, de sociabilidades e de relações de poder e simbólicas? Se a resposta for afirmativa, quais são as mediações? Se negativa, como se relacionam as questões que perpassam as lógicas das reestruturações produtivas e as dimensões da produção da heterogeneidade sobre a homogeneização?

Trata-se ainda de perguntar, portanto, como se integram (e em que âmbito se integram) estas diferentes lógicas, tanto no que se refere aos modos de gestão do trabalho, como em uma instância mais abrangente, os modos de regulação da relação salarial que, como apresenta a quase totalidade dos relatórios de pesquisa, parece encoIher em relação à forma clássica da produção em massa. Dessa maneira, a partir dos tratamentos das bases de dados, em especial Rais (presente em pelo menos três relatórios, a saber, Élida Liedke, Nadya Castro e Cibele S. Rizek e Leonardo Mello e Silva), pode-se notar um visível encolhimento do mercado formal de emprego em diferentes setores 
e regiões do país. Tal "encolhimento" pode ser visto sob o prisma de uma medida que turva, nublando horizontes de expectativa de sociabilidades que se amparavam em uma perspectiva de "integração" no mercado de trabalho. Outro elemento digno de nota é um patamar de relações empresas/trabalhadores que supõe, de maneira solidária a este encolhimento dos vínculos formais de trabalho, uma busca de deslegitimação das forças sindicais e uma diminuição de seu poder de negociação. Ao que tudo parece indicar, este parece ser um dos motes das gerências, como se pode observar pelos resultados parciais das diversas investigações (ver relatórios Castro, no caso da empresa petroquímica baiana, e Rizek e Mello e Silva, no caso da empresa de higiene bucal no $A B C D$, bem como as preocupações sindicais em relação à manutenção no emprego, como no caso dos químicos, em São Paulo, e dos bancários e metalúrgicos, no Rio Grande do Sul).

Cabe notar, ainda, que se algumas empresas têm por base a dimensão de uma reestruturação basicamente focalizada nas suas estratégias de negócios, nos padrões de fusão e compra, cuja principal determinação é financeira e não produtiva, outras vêm passando por transformações importantes no interior das formas e dos conteúdos da organização do trabalho, introduzindo ou requalificando a divisão sexual do trabalho, por estratégias de focalização que alteram pouco a lógica taylorista/fordista que lhes garantiu sucesso mercadológico (ver o caso da empresa A de higiene bucal no ABCD paulista). Nesse caso, a reestruturação é sinônimo de focalização, mantendo a forma de integração vertical que caracterizou desde sempre a estrutura da empresa. Nota-se, porém, que mesmo que a reestruturação assuma a forma de uma celularização taylorizada ou de uma retaylorização, ou de mediações principalmente financeiras, o padrão anti-sindical, pela individualização dos trabalhadores, pelo incremento qualitativo e quantitativo de seus vínculos de envolvimento com a empresa, está presente nos discursos sobre a "modernização" e a reestruturação industrial brasileira.

Dentre as muitas formas de reestruturação com ou sem a manutenção da lógica da produção em massa, ou dentre as várias combinações possíveis entre especialização flexível e formas tayloristas, bem como formas de trabalho invisibilizado, precarizado etc., parece haver um âmbito que perpassa o conjunto de relações industriais que basicamente poderia ser visto pela ótica da percepção e negociação de conflitos que, de alguma forma, pressupõe a existência de laços importantes de trabalho e de sociabilidade que constituem o coletivo de trabalhadores, que persistem ou constroem identidades e formas de repre- 
sentação, de um lado; ou da ótica do encapsulamento e da denegação dos conflitos, da individualização dos trabalhadores, do afastamento das formas de luta e/ou resistência fabril e sindical. Pode-se formular uma direção de análise que aponta para o fato de que estas duas formas de montar um padrão de relações entre empresas e trabalhadores desembocam em usos diversos de trabalho e, portanto, dos saberes desenvolvidos quer pelo incremento do estoque de conhecimentos, quer pela experiência de trabalho, isto é, das qualificações explícitas e tácitas, que podem ser pensadas na matriz de um uso individualizado (o que requer um padrão de disposições subjetivas nucleadas pelo envolvimento e pela adesão individual, ou outro padrão, pelo qual este saber construído de modo socializado é utilizado e mobilizado sem a quebra do coletivo e de sua identidade).

Estas perguntas, além de apontarem eixos importantes, cujas respostas raramente podem ser simplesmente do tipo afirmativo ou negativo, dada a diversidade anterior de faces e contrafaces, ora homogeneizadas, ora diferenciadas pelos processos recentes, remetem para uma gama variada de preocupações. Como avaliar e mensurar os resultados da reestruturação em termos do empowerment dos trabalhadores ou de seu contrário, sua neutralização? O mesmo pode ser estendido às dimensões de sua qualificação, apesar das evidências de uma exigência maior de escolaridade, o que em si pode ser uma qualificação requerida sem que os conteúdos de trabalho sejam, de fato, alterados. A questão pode ser ainda pensada em relação à participação e seus significados, que pode ter desdobramentos contraditórios.

Há, assim, uma diversidade de situações sobre as quais incidem os processos de reestruturação produtiva. Tais processos criam e recriam outras configurações que ora aprofundam, ora aproximam situações diversas entre si. Neste conjunto de lógicas e processos de diferenciação e segmentação da produção, encontram-se caminhos de construção de relações industriais cujos resultados no tempo atuam e configuram perspectivas basicamente distintas no que se refere à dimensão do conflito e do consenso entre gerências e trabalhadores.

Nesta direção o que se quer discutir é basicamente uma suposição explicitada de modos diversos que afirma uma ou outra lógica modelar a partir da qual todos os contextos fabris passariam a ser remodelados. Assim, parte da literatura sobre a reestruturação produtiva estaria apontando para uma reflexão que toma o modelo pelo real, 
enfatizando sua performance virtuosa, ou pelo seu exato contrário na perspectiva de sua demonização.

Alguns autores, tanto na literatura nacional como internacional, vêm insistindo em um processo de desidentificação entre as realidades fabris e a inexorabilidade dos modelos pelos quais se encenam trabalhadores dotados de iniciativa, qualificação e autodeterminação, ou seu contrário simétrico, o reforço da lógica fordista em relação aos conteúdos do trabalho (Castro 1993; Babson 1995 e Leite e Silva 1991). De certa forma, a produção recente de Oliveira (1993) pode ser lida como insurreição contra o reconhecimento de uma inexorabilidade, apontando para a possibilidade de negociação e interlocução entre patronato, Estado e trabalhadores capaz de alterar o cenário de uma reestruturação e globalização, cujos resultados apareciam como que dotados das qualidades de forças naturais.

Imprimir a lógica de tipos ideais, assimilados a modelos, supõe, assim, uma redução e um obscurecimento de um sem-número de possibilidades abertas em diferentes situações, de escolhas, de formas que supõem graus diversos de controle, produção do consentimento, absorção ou explicitação de conflitos, que se revestem ora de um investimento gerencial importante na individualização dos trabalhadores, na produção de sua adesão ou envolvimento como indivíduos, ora na construção de formas de ação em que constroem e reconstroem identidades coletivas. Estas diferentes possibilidades podem, portanto, construir fronteiras móveis de controle, pontos diversos de fusão entre adesão e resistência, novas formas de sociabilidade e socialização, ou a mera reposição de formas de dominação em que os usos anteriores do trabalho, que caracterizavam a lógica da produção em massa, ou mesmo as formas de gestão que, historicamente, Ihes são anteriores são mantidos ou repostos.

Este olhar que insiste na dimensão de que as formas de produção e trabalho fabril se tecem a partir de decisões e escolhas, de dimensões políticas que supõem atores cujo espectro de ações possíveis e de representações simbólicas produz tessituras diversas em escalas também diversas, repõe a questão da produção como questão sociológica fortemente politizada, afastando-se das perspectivas que enxergam as muitas combinações entre diferentes formas e regimes fabris como lógicas modelares.

Entretanto, como se pode depreender da literatura nacional emergente e de alguns autores, como Babson, consultores e gerentes apresentam modelos como promessas cuja aplicação supõe um percurso naturalizado e, portanto, determinado: 
Como um paciente ansioso que enfrenta uma doença de longa duração, os gerentes procuram um remédio que restaure a lucratividade. Uma cura milagrosa sucede a outra e cada uma promete mais do que pode cumprir. Os macroelixires de desempenho econômico e livre mercado são complementados, no nível micro, pela proliferação de planos baseados nas empresas, em sua maior parte, inspirados na patenteada fórmula japonesa. (Babson 1995, p. 15)

E, ainda, analisando o coração do debate sobre o impacto da produção enxuta, caracteriza-o da maneira que se segue:

Se, como os advogados deste novo sistema argumentam, há uma "mão oculta" que obriga a gerência a conferir poder em vez de explorar os trabalhadores - sob pena de perder o objetivo da performance que a produção flexível enxuta promete então os sindicatos são supérfluos. Mas, e se não houver este equilíbrio inerente que traga os interesses dos trabalhadores e das gerências a um alinhamento automático? Medo do desemprego ou a pressão dos pares de equipes dominados pela empresa podem realmente conduzir a normas de esforço que os trabalhadores individuais não teriam escolhido em outras condições.

Quais seriam os limites deste processo? Sua direção não aponta para o reforço de uma divisão entre um core de trabalhadores "privilegiados" e um conjunto de outros indivíduos atirados ao desemprego?

Como se pode perceber, apesar e por causa da implantação de remédios e planos, não há, de fato, certezas para além das promessas e dos receituários. Mais do que isso, as relações industriais estariam fortemente mediadas, não apenas pelas fronteiras móveis do controle, do consentimento e da resistência, mas também por formas de regulação societais que põem em xeque, tanto no âmbito nacional como internacional, os limites da ação do "livre-mercado", "que favoreceriam rendimentos deformados e precários". Deformados porque recompensam as empresas que pagam menos e exigem mais dos trabalhadores, subestimando os valores da eqüidade e da justiça, constitutivos da vida democrática; precários porque esta curva descendente em relação a um denominador aceitável de salários e condições de trabalho não tem fim. 
A competição, em resumo, tem duas faces. Seu lado positivo é celebrado pelas eficiências a que ela induz em qualquer empresa, e esta dimensão de competição global premia trabalhadores providos de poder que podem resolver problemas e continuamente melhorar o sistema. As evidências sugerem que setores sindicalizados, pela certeza de uma força de trabalho mais investida de poder genuíno, são mais produtivos e assim mais capazes de produzir competitividade do que os locais sem sindicatos, onde o trabalho é mais coercitivo. Entretanto, a competição tem uma outra face, menos celebrada. O lucro, não a mera eficiência, é o objetivo último da economia empresarial, e as pressões competitivas combinadas com o chamariz da lucratividade a curto prazo podem tornar atraente para as gerências a destituição do poder da força de trabalho: setores sindicalizados podem ser mais produtivos, mas ambientes de fragilidade sindical podem ser mais lucrativos se as poupanças advindas dos baixos salários e do trabalho intensificado compensarem os altos custos da rotatividade e as ineficiências de uma força de trabalho intimidada. Nestas circunstâncias, a competição desenfreada transforma o empowerment no seu oposto: cortando o pessoal até os níveis mínimos e forçando uma intensificação do trabalho pelos trabalhadores sobreviventes; definindo cada segundo do tempo dentro do ciclo do trabalho como ócio e desperdício a ser eliminado; seus pares a pressionarem os trabalhadores com restrições médicas, ausentes, ou os mais lentos e fracos. (Babson 1995, p. 31)

Aqui é possível comentar estas observações de modo a cotejá-las com a realidade empresarial brasileira que, ao que os relatórios parciais parecem indicar, nada tem de virtuosa. Ao apontar uma antinomia entre lucro e eficiência, o que pode ser sugerido é uma diferença de telos ou finalidade que imprime uma diversidade de tempo. O lucro, objetivo a curto prazo, estaria assim na contramão de uma dimensão de eficiência que supõe partilha, negociação, empowerment da força de trabalho sem privá-la de sua disposição, de sua configuração e de suas identidades coletivas. Talvez o melhor exemplo de caminho virtuoso, deste ponto de vista, tenha sido a experiência das câmaras setoriais do setor automotivo, ainda que com resultados diferentes entre as empresas, resultados estes tão mais impressionantes, quanto maior e mais estruturado o poder de negociação dos trabaIhadores e de suas entidades representativas. ${ }^{3}$ Por outro lado, nos dados que temos disponíveis nos relatórios parciais não é o caminho virtuoso que predomina. ${ }^{4}$ Os percursos de reestruturação estão continuamente apontando tanto do ponto de vista micro como do ponto de vista macro um caminho que aposta no curto prazo, no lucro imediato, no encapsulamento dos conflitos e na intimidação dos trabalhadores por um mercado de trabalho for- 
temente excludente. Além disso, é possível afirmar que esta aposta se vê firmemente ancorada em um conjunto de ausências no que se refere a uma conjuntura e uma forma de regulação, que aponta para políticas públicas assentadas em uma concepção bastante conservadora do ponto de vista do desestímulo à interlocução e à negociação. Mais uma vez aqui, há uma aceitação de horizontes que impõem medidas e concepções vinculadas a uma modernização globalizada sem mediações. Cabe, entretanto, ressaltar que este processo resulta de um conjunto de decisões que se tecem transversalmente entre os âmbitos micro e macro, das empresas em reestruturação à trama das políticas sociais que, largamente, se colocam na matriz de uma perversa combinação: de um lado, a contração do mercado de trabalho; de outro, a destituição de direitos e de poder real de negociação.

Assim, detectar possibilidades passa a ser um caminho de enunciação de tendências que não podem se confundir com a trama complexa, constitutiva e constituída por atores, suas possibilidades e seus constrangimentos, seus universos simbólicos e seus patamares de interlocução, negociação, conflito. Essa mediação parece ser, como reconhece parte da literatura internacional e nacional, fundamental para a compreensão em cada caso dos muitos rumos possíveis do processo de reestruturação industrial. Nem modelos, nem lógicas apresentadas monoliticamente como inexoráveis podem dar conta dos caminhos múltiplos, de objetivos diversos, de horizontes que se voltam para o lucro ou para a eficiência. Tais afirmações, porém, não ignoram as grandes dificuldades colocadas pelos rumos do mercado de trabalho, em âmbito mundial, tampouco as dificuldades e os desafios colocados para o movimento sindical, mas tratam de percebê-los em um quadro complexo cuja viabilização supôs e continua colocando conflitos de toda ordem, decisões e escolhas, atribuindo lugares para a força de trabalho e suas instâncias representativas que lhes conferem a qualidade de mero custo, o que não se configura como único, nem necessariamente o melhor caminho a seguir.

O quebra-cabeça das segmentações

Seria importante considerar, em primeiro lugar, que a perspectiva adotada pela maior parte das equipes de analisar a qualificação a partir dos complexos e das cadeias produtivas se mostrou bastante interessante, tendo em vista que os resultados preliminares apontam no sentido de um amplo espectro de heterogeneidades intra-setoriais com diferentes implicações sobre a força de trabalho. 
Assim, por exemplo, o relatório de Nadya Castro evidencia, através de um estudo de caso na petroquímica baiana, que, se por um lado, pode se detectar que "a crescente autonomização do trabalho de operação de campo e o aumento da importância da operação via console reúnem nas mãos do operador de processo um conhecimento mais amplo sobre o processo produtivo, abrindo-Ihes a possibilidade de maior diálogo com a engenharia" (relatório, p. 77), assim como o aumento das horas de treinamento dos empregados (p. 102), por outro lado, isso não significa o fim do trabalho pobre em conteúdo, mas apenas seu deslocamento para os terceirizados (p. 102). Quando se pensa em correlacionar o complexo produtivo com as segmentações do mercado de trabalho, as diferentes implicações do processo para os vários setores da mão-deobra tornam-se ainda mais evidentes, conforme elucida o estudo sobre a composição do setor químico no estado de São Paulo: embora as empresas venham em geral buscando uma mão-de-obra mais escolarizada, a escolaridade incide de forma diferente entre os trabalhadores de acordo com variáveis atributivas da força de trabalho, como sexo. Com efeito, o encolhimento do mercado de trabalho ocorrido nos últimos anos (especialmente a partir de 1989) vem incidindo de forma diferente entre os homens e as mulheres, na medida em que a maior escolaridade das mulheres não lhes assegura melhores condições de inserção no mercado de trabalho. Pelo contrário, conforme explicita Castro (pp. 66-67), "elas estão sujeitas a taxas de rotatividade (e, portanto, de instabilidade) no emprego muito maiores que a dos homens e coerentemente com isso têm menos tempo de emprego e estão em maior proporção nas empresas de pequeno porte que usualmente pagam menos".

Também o relatório de Cibele Rizek, sobre os químicos de São Paulo, aponta para a segmentação de gênero no que se refere aos requerimentos de qualificação e à formação da mão-de-obra:

\footnotetext{
O que se está afigurando com relação à formação profissional no caso dos químicos é uma segmentação entre os técnicos que vão trabalhar na petroquímica, técnicos de laboratório, técnicos químicos etc., que são formados na escola chamada "Centro Nacional de Tecnologia SENAl' em São Bernardo do Campo, específico de químicos, plásticos, cerâmica e borracha, e os operadores de processos químicos e petroquímicos que são formados no Centro Tecnológico de Mauá. Num caso, para funções mais qualificadas, uma escola; noutro caso, para funções menos qualificadas, outra escola. Essa hipótese persegue uma segmentação de formação que é paralela à segmentação do complexo entre
} 
processos químicos em fluxo, de caráter mais qualificado, e processos mecânicos, de caráter mais banalizado, do qual fazem parte, por exemplo, as seções de embalagem e montagem, onde imperam o trabalho repetitivo e as tarefas prescritas, e onde suspeita-se estar majoritariamente alocada a parcela feminina da força de trabalho. (p. 36)

Essas reflexões se complementam com os "achados" da pesquisa na empresa $A$, onde o trabalho com as máquinas do setor de laminação

\begin{abstract}
obedece à mais estrita lógica taylorista da quantidade, da unidade entre trabalhador, posto e tarefa. A qualificação requerida é obtida da forma como se descreve normalmente pela expressão "ao pé da máquina". O treinamento é realizado no próprio setor e quando o novo operador está "pronto", seu trabalho é monitorado por um operador mais antigo... Note-se que, neste setor privilegiado nas estratégias de transformação, predomina o uso taylorizado do trabalho feminino. (p. 40)
\end{abstract}

A relação entre trabalho taylorizado ou destituído de conteúdo e mulheres aparece também de forma evidente no relatório da equipe da coordenação, em que a multifuncionalidade das mulheres se reduz à integração das tarefas de colar e costurar uma peça de couro em torno do volante. Outra forma de segmentação que aparece em vários dos subprojetos é a que se refere à idade. Nadya Castro, por exemplo, sublinha que no setor químico do estado de São Paulo, os jovens também foram relativamente mais afetados pelo encolhimento do mercado do que os de mais idade, apesar de disporem, via de regra, de níveis de escolaridade superiores do que os mais maduros.

Cabe destacar, entretanto, que as tendências à segmentação do mercado de trabalho nem sempre se expressam da mesma maneira, havendo inclusive casos de tendências opostas entre os vários setores. Por exemplo, no que se refere à segmentação de gênero, parece haver mais espaço para o crescimento profissional das mulheres no setor bancário do que nos diferentes setores industriais, tendo em vista a tendência de ascensão das mulheres a cargos de gerência nos bancos (relatório Liedke). As divergências parecem ainda maiores quando se pensa na questão da idade. De fato, enquanto para a petroquímica, 
de acordo com o relatório de Nadya Castro, bem como para o setor bancário (conforme o relatório de Élida Liedke), parece estar havendo uma preferência pelo trabalho adulto, o mesmo não acontece com o setor metalmecânico e eletroeletrônico do Rio Grande do Sul, onde, segundo o relatório de Élida Liedke,

\begin{abstract}
observa-se crescente preferência por mão-de-obra mais jovem nos critérios de recrutamento e seleção, uma vez que a substituição do trabalhador mais especializado (...) torna-se facilitada através do emprego de jovens que estão ingressando através do mercado de trabalho e que não apresentam resistências para a execução de novas tarefas associadas às inovações. (p. 49)
\end{abstract}

Conclusão

O conjunto de dados disponibilizados pela pesquisa aponta para um quadro bastante heterogêneo no que se refere às implicações do processo de reestruturação produtiva para a qualificação da mão-de-obra.

Contrapondo-se às análises criticadas anteriormente, que tendem a considerar os processos de reestruturação a partir de modelos (quer sejam eles virtuosos, como o da especialização flexível, quer sejam baseados na precarização), tais dados indicam que trabalhos precarizados e multiqualificados parecem conviver não só em diferentes setores, mas também em diferentes empresas dentro de um mesmo setor e, inclusive, entre diferentes setores da mão-de-obra dentro de uma mesma empresa. Nesse sentido, se o conceito de cadeia ajuda a compreender as diferenças intra-setoriais (conforme evidencia o relatório da coordenação), as diferenças entre os distintos setores da mão-de-obra no interior das empresas remetem ao conceito de qualificação como uma construção social, só podendo ser compreendidas a partir da análise das discriminações sociais que informam as políticas de gestão da mão-de-obra.

As implicações sociais da inovação tecnológica não estão, portanto, inscritas no potencial tecnológico, mas nas relações sociais que presidem a utilização da tecnologia. E, se tivermos presente, conforme nos ensina Babson, que quanto mais democráticas as relações sociais, mais virtuoso tende a ser o processo, teremos também em mente não 
só a importância de o processo ser negociado. Mais que isso, teremos presente que a questão da qualificação não se resolve apenas pela multiplicação de cursos de formação profissional, mas necessita também levar em conta o acesso aos cursos, a definição de seus conteúdos, a forma de geri-los, entre outros fatores, para os quais a participação sindical na definição das políticas é fundamental, conforme indicam os "achados" internacionais de que os programas mais exitosos tendem a ser os que contam com a participação dos sindicatos. A definição de políticas públicas que contemplem fóruns de discussão e negociação de tais questões com a participação de sindicatos de trabaIhadores, empresários e governos se apresenta dessa forma tão importante quanto a oferta de cursos e deve, sem dúvida, merecer a atenção dos órgãos governamentais.

\section{Notas}

1. Convém elucidar que, embora concordemos com os críticos da idéia de um novo paradigma produtivo que o princípio de intensificação do trabalho através da diminuição dos poros da jornada continue por trás da lógica da produção como esteve no taylorismo, não acreditamos que isso significa que a lógica taylorista continue prevalecendo. Na verdade, tal princípio nos parece constitutivo do próprio capitalismo, estando, portanto, presente em qualquer dos modos de acumulação por que vem passando a produção industrial desde seus primórdios. Os princípios que, a nosso ver, caracterizam o taylorismo/fordismo como forma de organização do trabalho (a produção em massa de produtos estandardizados, a parcelização das tarefas, a divisão entre trabalho manual e intelectual, os tempos impostos, o trabalho individualizado e colocado sob vigilância da pesada hierarquia fabril) encontram-se sem dúvida na linha de fogo dos novos conceitos de produção, embora, conforme veremos a seguir, isso não signifique que eles estejam sendo inteiramente abandonados, mas, em muitos casos, apenas redimensionados e inseridos em novas lógicas.

2. Schmitz (1993, p. 141), por exemplo, avança na hipótese de uma tendência ao high road nos países centrais, em contraposição a uma maior inclinação dos países periféricos em relação ao low road. De acordo com o autor, isso se deveria ao fato de que um caminho baseado em baixos salários seria a via mais provável de se desenvolver nos países do Terceiro Mundo em virtude do enorme estoque de mão-de-obra sobressalente. Em contraste com essa situação, nos países centrais, mesmo quando há altas taxas de desemprego, o seguro-desemprego tende a garantir que o salário não desça abaixo de determinados níveis, favorecendo o desenvolvimento de uma dinâmica mais baseada na qualidade dos produtos. 
3. Não se pode deixar de considerar aqui que as informações coletadas pela equipe de Alice Abreu, evidenciando o peso da questão sindical na escoIha do local da nova fábrica da Volkswagen, apontam para uma alternativa bastante diferente no que se refere às relações com o sindicato. (Relatório Abreu)

4. Cabe lembrar aqui que a exceção pode ser pensada a partir da montadora que vem sendo pesquisada pela equipe da coordenação. Todavia, embora essa empresa possa ser apresentada como um exemplo do caminho virtuoso, em função do processo de negociação da reestruturação em curso desde o início dos anos 90, a negociação não foi suficiente para impor um caminho virtuoso ao longo de toda a cadeia. Isso significa que, em vez de as condições encontradas na montadora serem replicadas por toda a cadeia produtiva, o que se observa é que tais condições são mantidas a expensas das condições de trabalho observadas no resto da cadeia.

\section{Project: Productive restructuring and qualification}

ABSTRACT: This text is a partial report of a year-long project entitled "Productive restructuring and qualification". It discusses the first findings of several sub-projects that comprise the main project, giving special emphasis to the present segmentation in the working arena.

\section{Bibliografia}

BABSON, S. "Lean production and labor: Empowerment and exploitaton". In: Steve Babson (org.). Lean work: Empowerment and exploitation in the global auto industry. Detroit, Wayne State University Press, 1995.

CASTRO, N. "Modernização e trabalho no complexo automotivo brasileiro". Novos Estudos Cebrap nํ 37. Novembro de 1993.

KERN, H. e SCHUMANN, M. El fin de la division del trabajo. Madri, Ministerio de Trabajo y Seguridad Social, 1988.

LEITE, M. e POSTHUMA, A. "Reestruturação produtiva e qualificação: Reflexões sobre a experiência brasileira”. São Paulo em Perspectiva no 1.1996 , vol. 10.

LEITE, M. e SILVA, R. "Tecnologia moderna e relações de trabalho conservadoras: A contradição brasileira?" In: Leite e Silva (org.). Modernização tecnológica, relações de trabalho e práticas de resistência. São Paulo, Iglu/lldes/Labor, 1991. 
OLIVEIRA, F. "Quanto melhor, melhor: O acordo das montadoras", Novos Estudos Cebrap № 36. Julho de 1993.

SCHMITZ, P. "Toyotismo e/ou japonização". In: Helena Hirata (org.). Sobre o modelo japonês. São Paulo, Edusp, 1993.

SENGENBERGER, W. e PYKE, F. "Industrial districts and local economic regeneration: Research and policy issues". In: Pyke e Sengenberger (orgs.). Industrial districts and local economic regeneration. Geneva, International Labour Organization, 1992.

ZARIFIAN, H. "Small firms and flexible specialization in decloping countries". In: Spath (org.). Small firms and development in Latin America. Genebra, International Institute for Labour Studies, 1993. 